\title{
Primary synovial chondromatosis: an elemental investigation of a rare skeletal pathology
}

\author{
A.W. Beger'1, J.A. Millard', A. Bresnehan'1, B. Dudzik1®อ, S. Kunigelis² \\ ${ }^{1}$ Anatomy Department, DeBusk College of Osteopathic Medicine, Lincoln Memorial University, Harrogate, \\ TN, United States of America \\ 2Physiology Department, DeBusk College of Osteopathic Medicine, Lincoln Memorial University, Harrogate, \\ TN, United States of America
}

[Received: 23 April 2021; Accepted: 7 May 2021; Early publication date: 25 May 2021]

Background: Primary synovial chondromatosis (PSC) is a rare idiopathic pathology characterised by the formation of osseocartilaginous nodules within synovial joints, tendons, or bursae. The mineralisation pattern of PSC nodules is poorly understood and has yet to be investigated using elemental analysis. Mapping this pattern could elucidate the progression of the disease.

Materials and methods: Primary synovial chondromatosis nodules discovered during dissection of a formalin fixed donor were analysed. Scanning electron microscopy paired with energy dispersive X-ray spectroscopy (SEM-EDS) was used to quantify calcium and phosphorus levels to distinguish mineralised components from cartilage, indicated by increased carbon and oxygen concentrations.

Results: Nine nodules with average dimensions $1.76 \mathrm{~cm} \times 1.25 \mathrm{~cm}$ were identified in the semimembranosus bursa. SEM-EDS demonstrated increased calcium phosphate levels in nodular cores, while outer margins contained primarily carbon and oxygen. Quantification of these elements revealed nodular peripheries to contain $68.0 \%$ carbon, $30.2 \%$ oxygen, $0.8 \%$ calcium, and $1.0 \%$ phosphate, while cores were comprised of $38.1 \%$ carbon, $42.1 \%$ oxygen, $14.1 \%$ calcium, and $5.7 \%$ phosphate.

Conclusions: Nodules were found to have mineralised cores embedded within a cartilaginous matrix. This pattern suggests disease progression is facilitated by endochondral ossification, opening the potential for new therapeutic techniques. (Folia Morphol 2022; 81, 3: 685-693)

Key words: scanning electron microscopy, energy dispersive X-ray spectroscopy, nodules, loose bodies, semimembranosus bursa, popliteal cyst

\section{INTRODUCTION}

Primary synovial chondromatosis (PSC) is a rare, benign pathology characterised by the proliferation of osseocartilaginous nodules from the synovial lining of joints, bursae, or tendinous sheaths [29]. Disease onset is marked by chondroid metaplasia, where synoviocytes aberrantly modify their phenotype to secrete a cartilaginous matrix comprised of type II collagen, which can coalesce to form deposits of hyaline cartilage $[1,27]$. These deposits can fuse, mineralize, and eventually ossify as intrasynovial loose bodies [28]. Secondary synovial chondromatosis has

Address for correspondence: Dr. A.W. Beger, Faculty for Anatomical Sciences, Edward Via College of Osteopathic Medicine - Virginia Campus, Blacksburg, VA, 24060, United States of America, tel: 540-231-1178, e-mail: abeger@vcom.edu

This article is available in open access under Creative Common Attribution-Non-Commercial-No Derivatives 4.0 International (CC BY-NC-ND 4.0) license, allowing to download articles and share them with others as long as they credit the authors and the publisher, but without permission to change them in any way or use them commercially. 
been described, where intraarticular loose bodies instead appear as a result of degenerative arthropathy or trauma $[10,16]$. PSC affects males up to 3 times more often than women [29] and is most often seen in the knee [25], although any synovial joint may be affected, including the hip [39], shoulder [38], and temporomandibular joint [4]. Patients often present with joint pain and swelling, limited range of motion, crepitus, or may be asymptomatic, depending on the stage, severity, and location of the condition [22, 33]. This ambiguous symptomatology makes the incidence rate difficult to estimate, but a rate of 1 per 100,000 has been reported [8]. In the presence of functional deficits, treatment will involve surgical extraction of loose bodies; synovectomy may also be recommended to prevent recurrence, although research has shown that it may have no influence on prognosis up to six years post-operation [36].

While researchers have done well to characterise various presentations of PSC, its label as an idiopathic condition persists. The limited understanding of disease progression is reflected in conflicting reports on the mineralisation patterning of osseocartilaginous nodules. Early investigators postulated that PSC nodules followed patterns of endochondral ossification, in which central mineralisation occurred within a cartilaginous matrix [26]. However, more recent reports describe ossification as first appearing peripherally, deviating from original claims [9]. Mapping the mineralisation pattern of PSC nodules through elemental analysis could clarify this discrepancy, while also providing evidence to assist with disease staging, medical imaging interpretation, and development of novel treatment options.

Scanning electron microscopy (SEM) coupled with energy-dispersive X-ray spectroscopy (EDS) conducts elemental analysis by first bombarding a sample with an electron beam. When a primary beam electron displaces a specimen inner shell electron, outer shell electrons move to replace it. Specific elements can be identified by their signature $\mathrm{X}$-ray energy levels released as specimen electrons move to lower energy level orbitals. The utility of SEM-EDS is well-represented in various fields of biology, including forensic anthropology [30], dentistry [7], bioarcheology [6], and biomedical research [24]. Despite its widespread applications in biological research, to the knowledge of the authors, the utility of SEM-EDS has yet to be leveraged in the elemental investigation of intraarticular loose bodies, including those caused by PSC.
The aim of this research was to employ SEM-EDS to clarify the patterning of mineralisation in PSC nodules discovered during anatomical dissection. Dissection images and radiographs were included to support the clinician's understanding of this rare condition.

\section{MATERIALS AND METHODS}

\section{Ethical approval}

This research received ethical approval by the Institutional Review Board (Ref. \#885V.1). Consent for the willfully donated tissue to be used for research purposes was provided by the donor premortem.

\section{Cadaveric dissection}

The right posterior knee of an 88-year-old formalin-fixed male donor was dissected by a group of first-year medical students. Investigation of the superomedial corner of the popliteal fossa revealed an enlarged semimembranosus bursa, situated between the semimembranosus tendon and medial head of gastrocnemius. Excision of the bursa revealed numerous hardened, semi-lobulated nodules bathed in synovial fluid (Fig. 1). Students followed similar protocols to dissect the left popliteal fossa, followed by bilateral intraarticular exploration of the tibiofemoral, patellofemoral, acetabulofemoral, and glenohumeral joints performed by an author (A.W.B.) to determine the extent of the pathology.

\section{Medical imaging}

Radiographs were taken to elucidate the patterning of mineralisation and in situ positioning of the nodules. Nodules were retained within the semimembranosus bursa as anterior-posterior and lateral radiographs were obtained (Del Medical Systems, model \#RT100).

\section{Sample preparation for SEM}

Following medical imaging, nodules were extracted, counted, and measured using Neiko digital callipers. Eight nodules were randomly selected and processed for ultrastructure inspection via coring, freeze fracture, or bisection. Three were cored by manually driving a bone marrow biopsy "J" type needle (Argon Medical Devices, Frisco, TX) through its centre. Three were suspended in a polyurethane ice bucket containing liquid nitrogen for $60 \mathrm{~s}$, and subsequently fragmented. Two were bisected by gently hammering a scalpel through their equator. 


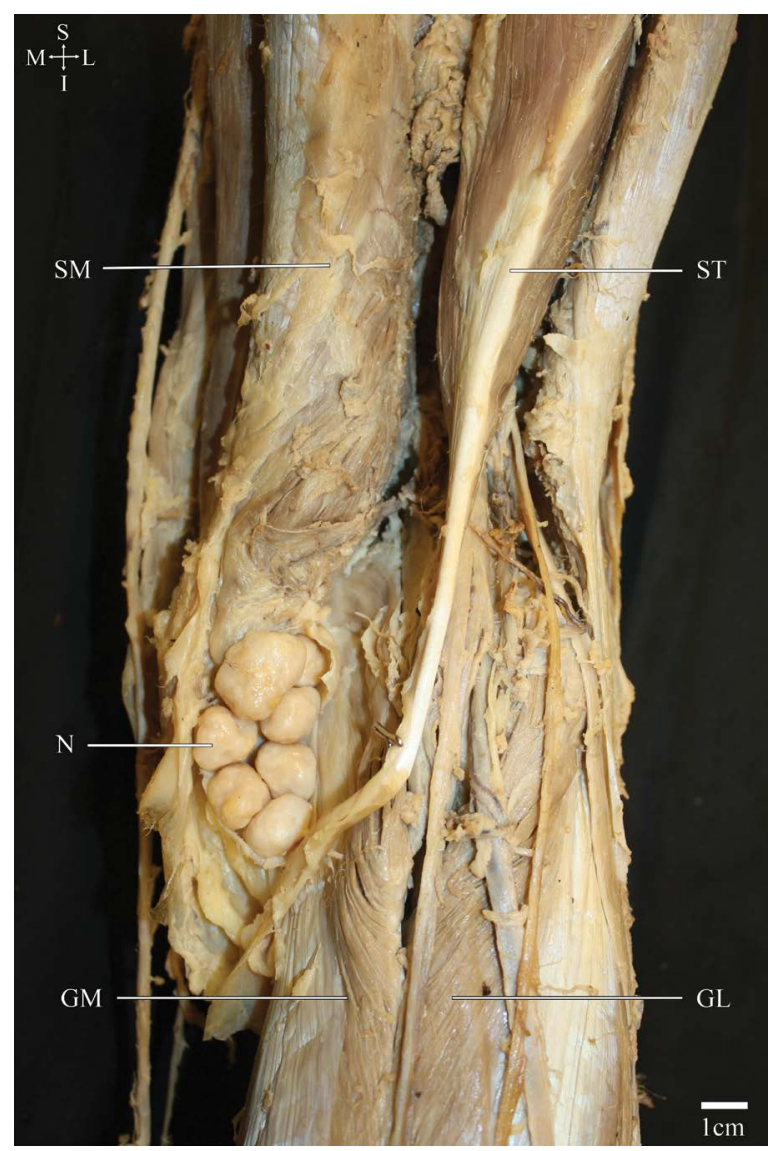

Figure 1. Posterior view of the right knee following dissection of the popliteal fossa. Skin and subcutaneous tissue have been removed. Nodules (N) were found within the semimembranosus bursa (incised), situated between the semimembranosus muscle (SM) and the medial head of gastrocnemius muscle (GM). Tendon of semitendinosus muscle (ST) is retracted laterally; $\mathrm{GL}$ — lateral head of gastrocnemius muscle; I — inferior; L — lateral; $\mathrm{M}$ — medial; S — superior.

Freeze fractured $(n=6)$, cored $(n=6)$, and bisected $(n=4)$ samples were fixed using phosphate buffer glutaraldehyde and osmium tetroxide, respectively. Following fixation, specimens were dehydrated using a graded series of ethanol ( $2 \mathrm{~h}$ each in $50 \%, 70 \%$, $85 \%, 100 \%$ and replenished $100 \%$ ) then further dried with hexamethyldisilazane ( $2 \mathrm{~h}$ each in $50 \%, 98 \%$, and replenished $98 \%$ ), with agitation throughout. Specimens were then mounted on $1 \mathrm{~cm}$ stubs and sputter coated using a gold-palladium target (Anatech USA Hummer 6.2 Sputtering System).

\section{SEM-EDS}

A Hitachi TM-3000 SEM was coupled with EDS (Bruker Quantax 70) to perform elemental analysis on the surface scans of samples. A targeted working distance of $8.3 \mathrm{~mm}$ was used to optimise X-ray detection. The concentrations of calcium, phosphorus, carbon, and oxygen in each sample were localised and quantified using the mapping, line scan, and spot mode EDS features. Mapping demonstrated patterning of elemental distribution across the entirety of the sample's surface, while line scan was used to depict fluctuations in the concentration of target elements along the length of a drawn vector. Spot mode quantified elemental composition within a target area, which was drawn with the smallest possible circumference so as to capture the narrowest window of X-ray counts required by the software to perform the analysis. Nodular cores and peripheries were targeted using this spot mode method to compare the elemental composition of these two regions. Results of line scan and mapping analyses were interpreted to describe the pattern and extent of mineralisation. Mineralised areas were indicated by increased concentrations of calcium and phosphorus, versus cartilaginous components as evidenced by the presence of primarily carbon and oxygen.

\section{Statistical analysis}

Nodule dimensions and results of elemental analysis were entered into Microsoft Excel (Microsoft Office 365 , Version 16.44) for descriptive statistical analysis.

\section{RESULTS}

\section{Cadaveric dissection}

Nine total nodules were found within the right semimembranosus bursa (Fig. 1). Dissection of the left semimembranosus bursa revealed numerous cartilaginous deposits within the synovial membrane. No loose bodies were identified. Dissections of the patellofemoral, tibiofemoral, acetabulofemoral and glenohumeral joints were performed and were absent of cartilaginous deposits and loose bodies.

\section{Medical imaging}

Anterior-posterior and lateral plain radiographs of the right knee demonstrated the radiopaque nodules posterior to the knee joint (Fig. 2). Incidental findings included narrowing of tibiofemoral and patellofemoral joint spaces, osteophytic deposits on the distal femur and proximal tibia, and subchondral sclerosis denoted by increased radiopacity across the tibial plateau. Following extraction, nodules were found to have average dimensions of $1.76 \mathrm{~cm} \times$ $\times 1.25 \mathrm{~cm}$ (Fig. 3), with bisected samples depicting a central core of mineralisation and cartilaginous shell (Fig. 4). 

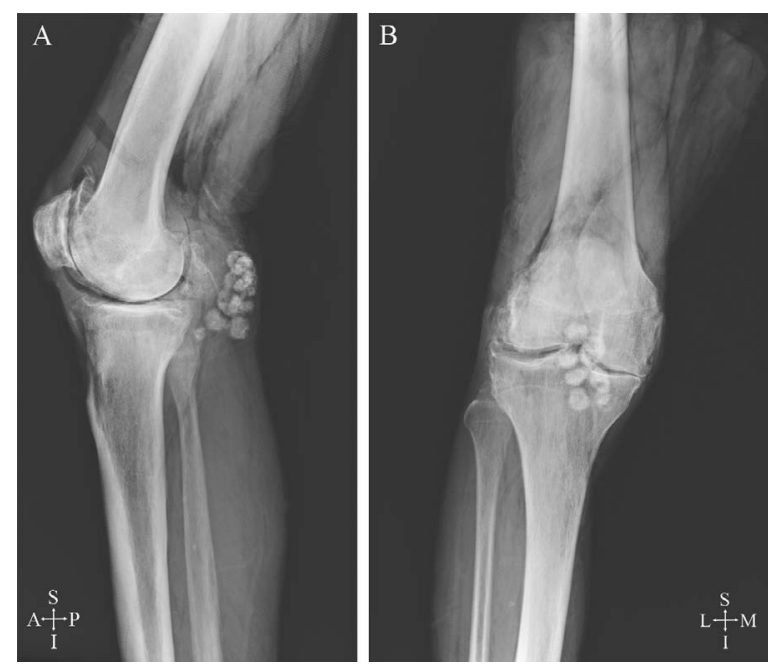

Figure 2. Lateral (A) and anteroposterior (B) radiographs of the right knee. Primary synovial chondromatosis nodules can be seen as collection of radiopacities posterior to the knee joint; $\mathrm{A}-$ anterior; I - inferior; L — lateral; $\mathrm{M}$ - medial; $\mathrm{P}$ - posterior; $\mathrm{S}$ - superior.

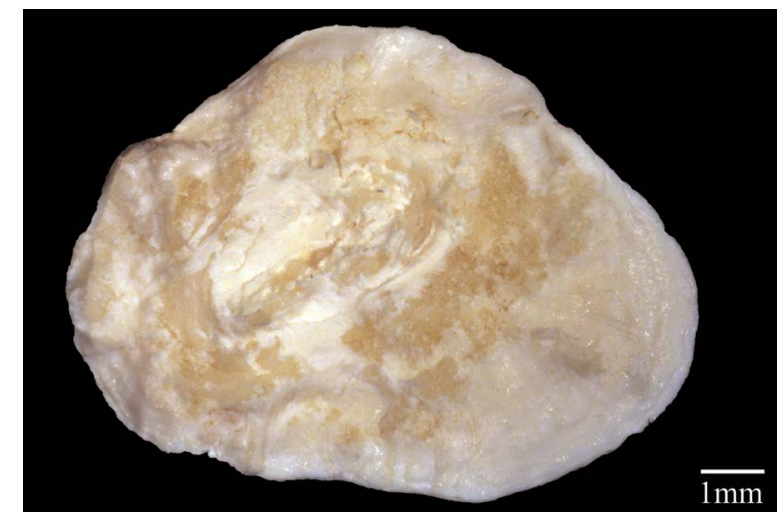

Figure 4. The inner face of a halved nodule depicts its internal morphology via light microscopy. Central swirl of mineralisation and outer cartilaginous shell can be seen. Intermediary lamellae of calcification support a gradient pattern of mineralization that is initiated centrally and proceeds towards the periphery.

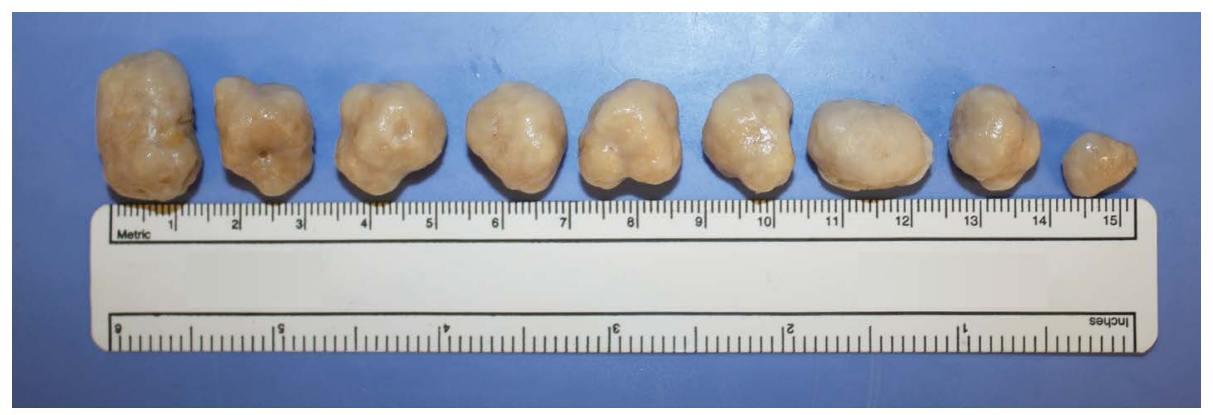

Figure 3. Isolated nodules $(\mathrm{n}=9$ ) following extraction from the semimembranosus bursa, with average dimensions of $1.76 \mathrm{~cm} \times 1.25 \mathrm{~cm}$.

\section{SEM-EDS}

SEM-EDS was used to detect the presence of carbon $(\mathrm{C})$, oxygen $(\mathrm{O})$, calcium $(\mathrm{Ca})$ and phosphorus $(\mathrm{P})$ as an indicator of phosphate in all freeze fractured, cored, and bisected samples using mapping, line scan, and spot mode features. Mapping depicted a gradient pattern of calcium and phosphate levels, with greater deposition of these elements near the nodular centre, with only trace amounts of these elements detected in the outer shell. Carbon and oxygen levels were found throughout, with higher concentrations in the periphery (Fig. 5A-C). Line scan showed similar results, with concentrations of calcium and phosphate being higher near the nodular centre then gradually decreasing towards the periphery. Thin, lamellar depositions of calcium and phosphate radiating outwards were observed (Fig. 5D-F), supporting light microscopic observations under low magnification (Fig. 4).
Spot mode analysis was performed in the centre and periphery of all samples, and further indicated a pattern of increased mineralisation in nodular centres as evidenced by higher concentrations of calcium and phosphate (Fig. 5G-I). Collectively, outer margins were found to be composed of $68.0 \% \mathrm{C}, 30.2 \% \mathrm{O}$, $0.7 \% \mathrm{Ca}$, and $1.0 \% \mathrm{P}$ (Fig. $6 \mathrm{~A}$ ), with nodular cores containing $38.1 \% \mathrm{C}, 42.1 \% \mathrm{O}, 14.1 \% \mathrm{Ca}$, and $5.7 \% \mathrm{P}$ (Fig. 6B).

\section{DISCUSSION}

Elemental analysis via SEM-EDS revealed PSC nodules to contain a mineralised core embedded in a shell of cartilage. This finding refutes recent claims that ossification is initiated peripherally [9], while supporting the original hypothesis put forth by Milgram [26] in 1971 that nodules contain outer margins of "lobular cartilage, with a central region of reactive 

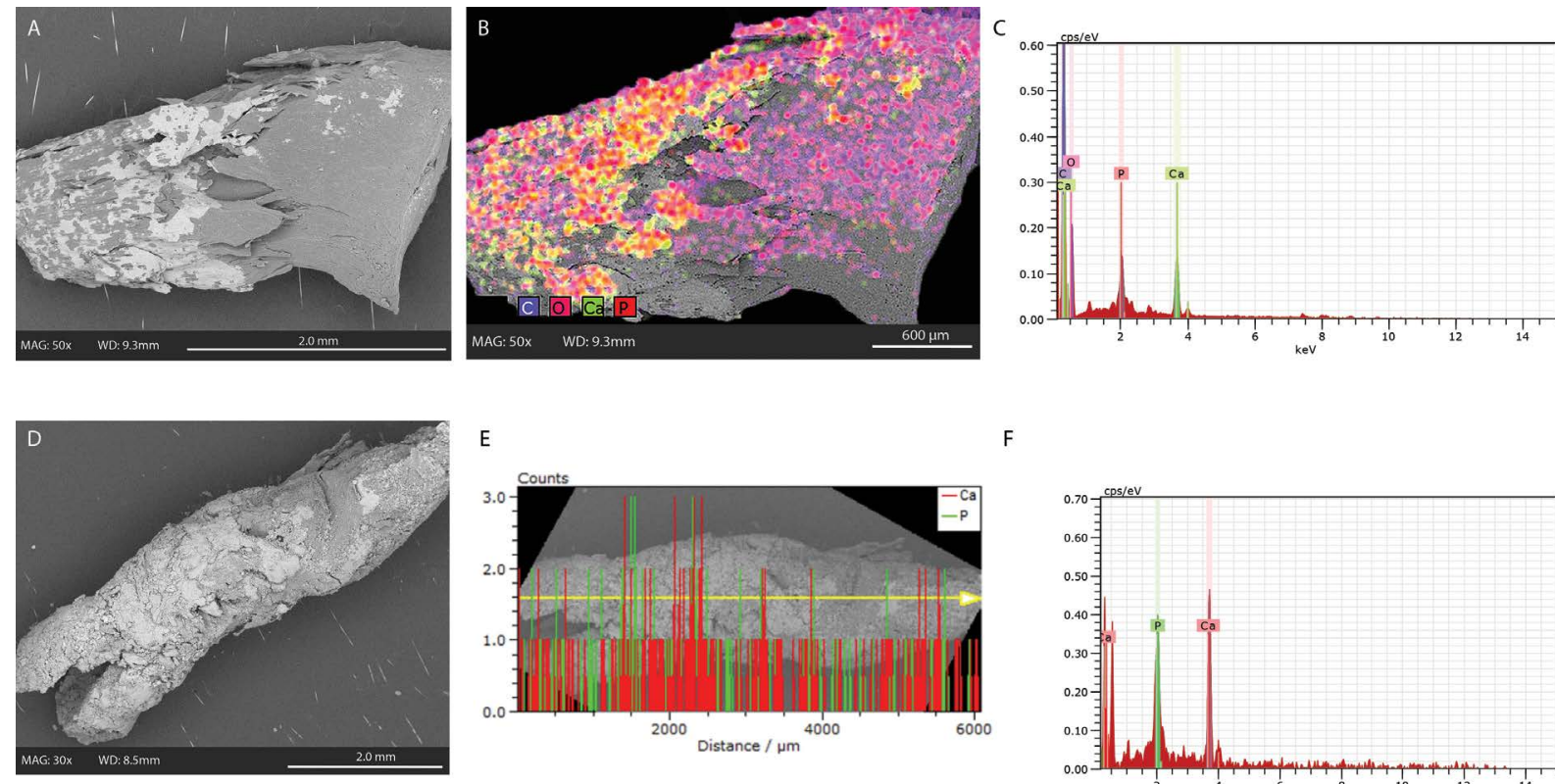

E

$\mathrm{F}$
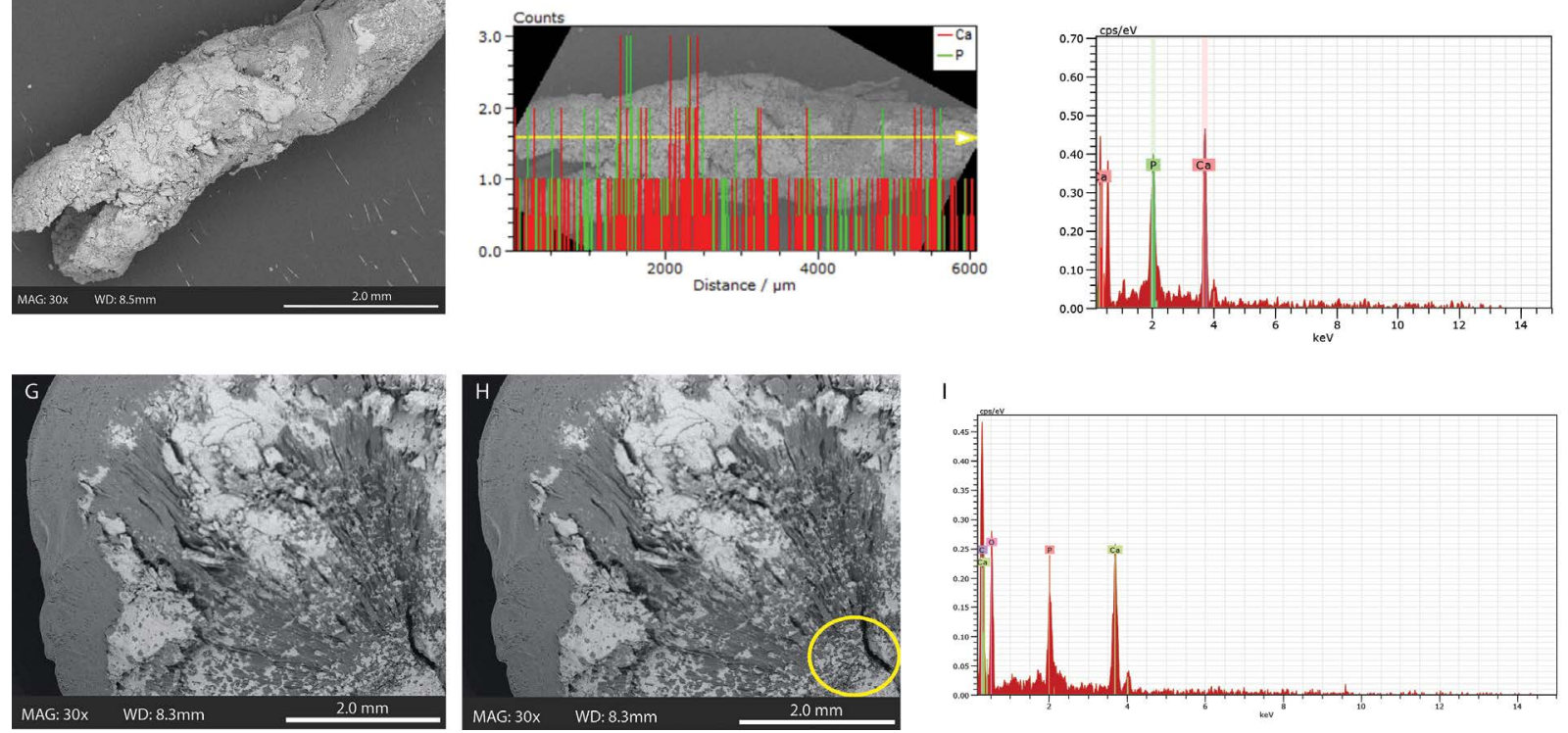

Figure 5. Scanning electron microscopy (SEM) paired with energy dispersive X-ray spectroscopy elemental analyses of primary synovial chondromatosis nodules; A. SEM image of freeze fractured sample, with centre of the nodule pointing the left; $\mathbf{B}$. Sample from panel A analysed in mapping mode, indicating higher levels of calcium $(\mathrm{Ca})$ and phosphorus $(\mathrm{P})$ in the core; C. Spectrum plot from analysis in panel $\mathrm{B}$, depicting elemental abundance in X-ray counts per second per electron volt (cps/eV), with elements identified via their kiloelectron volt (keV) signature; D. SEM image of cored sample, with centre of the nodule pointing to the bottom left; $E$. Sample from panel $D$ analysed in line scan mode, indicating lamellar deposits of $\mathrm{Ca}$ and $\mathrm{P} ; \mathrm{F}$. Spectrum plot from analysis in panel $\mathrm{E}$, depicting elemental abundance in $\mathrm{X}$-ray counts $\mathrm{cps} / \mathrm{eV}$, with elements identified via their keV signature; G. SEM image of halved nodule, with centre of the nodule located in the bottom right; H. The centre of bisected nodule (G) is analysed in spot mode; I. Spectrum plot from analysis in panel $\mathrm{H}$, depicting elevated levels of Ca and $\mathrm{P}$ in $\mathrm{X}$-ray counts $\mathrm{cps} / \mathrm{eV}$, with elements identified via their keV signature; $\mathrm{C}$ - carbon; 0 - oxygen; MAG — magnification; WD — working distance.

bone." Milgram [26] postulated that a remodelling process similar to endochondral ossification could be responsible for this pattern of central mineralisation. Endochondral ossification outlines the normal developmental processes involved the formation of the majority of the mammalian skeleton [20]. Briefly, this process begins with undifferentiated mesenchyme condensing to form precursors of skeletal structures. Mesenchymal stem cells in the centre of these precursors will differentiate into chondrocytes, which will form a model of the developing bone through secretion of a collagen matrix. Invasion of osteogenic cells promotes bone deposition in centrally located primary ossification centres. Meanwhile, chondro- cytes continue to proliferate at the margins of the developing bone, facilitating growth, while bone deposition proceeds centrally. Modulating endochondral ossification processes are a host of transcription factors. Members of the fibroblast growth factor (FGF) family like FGF1 and FGF2 have been shown to provide essential signalling for cell survival within condensing mesenchyme [42], and regulation of osteocyte proliferation and differentiation in developing bone [43], while chondrocyte proliferation is promoted by FGF3 and FGF9 [13]. Interestingly, dysregulation of these transcription factors has been described in the synoviocytes and chondrocytes of PSC, implicating their role in the aberrant cellular differentiation that 


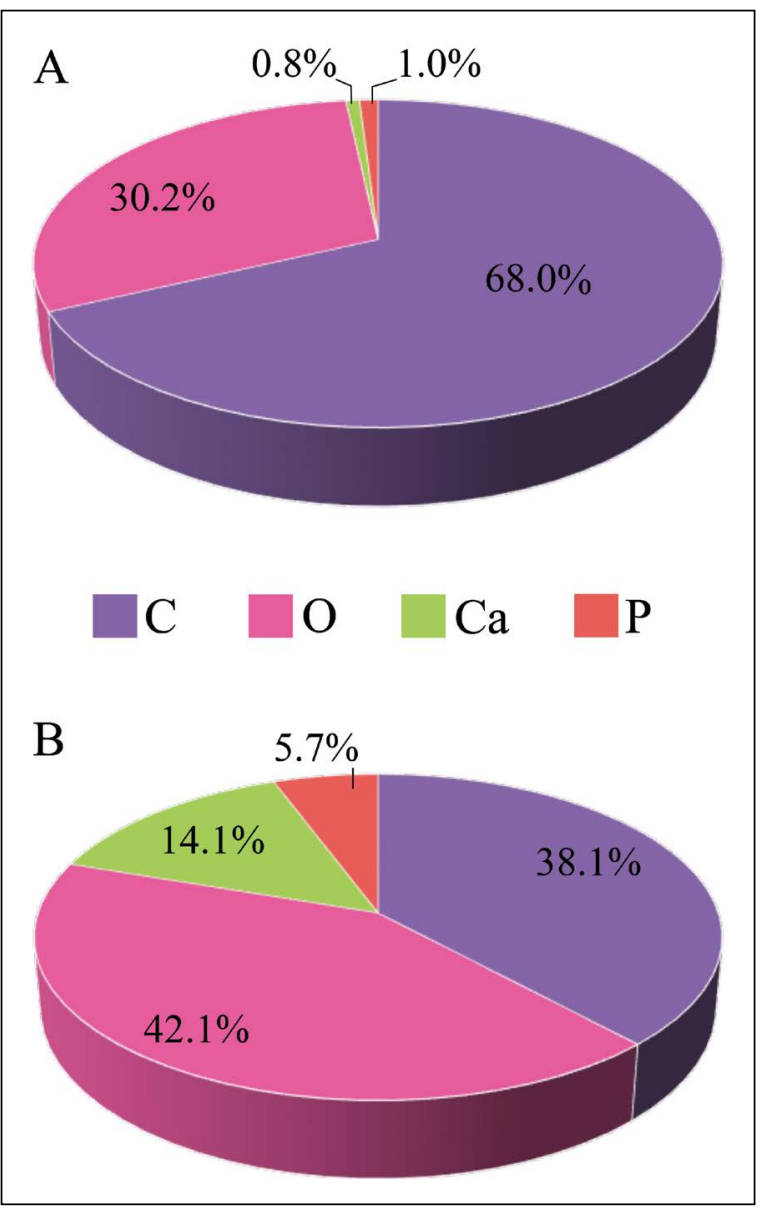

Figure 6. Pie charts depicting results of spot mode scanning electron microscopy paired with energy dispersive X-ray spectroscopy elemental analyses of cored, freeze fractured, and bisected specimens; A. Elemental composition of nodular periphery. High concentrations of organic elements (carbon and oxygen) suggest a predominantly cartilaginous composition; B. Elemental composition of the centre of nodules. Increased calcium and phosphate content suggest advanced mineralisation; $\mathrm{C}-$ carbon; $\mathrm{O}-\mathrm{oxy}$ gen; $\mathrm{Ca}$ - calcium; $\mathrm{P}$ - phosphorus.

is characteristic of the condition [31, 32]. Therapeutic interventions designed to target these molecular regulators could provide novel treatment options for PSC, not unlike those designed for ankylosing enthesitis, a chronic articular pathology that has been found to also manifest via endochondral ossification [21].

The progression of PSC has been outlined into three stages by Milgram [25]: stage I is marked by cartilaginous proliferations deposited within inflamed synovial tissue with no loose bodies present; stage II is distinguished by synovitis with well-formed nodules that may or may not have separated from the synovium to form loose bodies; stage III is characterised by the presence of intraarticular loose bodies with no active synovitis [25]. Applying Milgram's staging to the results from the cadaveric dissection in this study, a diagnosis of bilateral, extraarticular PSC could be postulated: cartilaginous deposits found in the synovial membrane of the left semimembranosus bursa suggest a possible stage I disease state, with the loose bodies in the right indicating stage III. Bilateral, extraarticular presentations of PSC have been reported [2] but are exceedingly rare. More research is required to investigate potential underreporting of bilateral cases when staging is asymmetrical, with the more conspicuous side possibly overshadowing the other.

Differential diagnosis for PSC includes secondary synovial chondromatosis, and loose bodies formed from a chondrosarcoma malignancy [41], a critical demarcation as each requires unique interventions. Diagnosis typically relies on a combination of patient history and a series of radiographic and histopathological studies [28]. The differing pathophysiology of these conditions is reflected in the distinct mineralisation patterns observed in their respective nodular products [26]. PSC nodules are described as being primarily composed of cartilage, with characteristic "ring-and-arc" mineralisation patterns seen in advanced stages of the disease [28]. In contrast, osteochondrosarcomas have been described to be more heterogeneous with ill-defined, lobulated margins and punctate calcifications [17]. Secondary synovial chondromatosis nodules, meanwhile, would depict a hyperdense, ossified core with a thin margin of articular cartilage, reflecting their origin from fragments of developed bone [26]. These characteristics highlight the importance of elucidating the mineralisation pattern of intraarticular loose bodies so as to further facilitate this differential diagnosis process and aid in their identification on medical imaging studies.

Incidental findings of the lateral and anteroposterior radiographs suggested an additional diagnosis of osteoarthritis, evidenced by decreased joint space, osteophyte formation, and subchondral sclerosis [14]. The association between osteoarthritis and PSC is still poorly understood, however, a histopathological link is possible since both are associated with cellular alterations of the synovium [34]. Better understood is the relationship between osteoarthritis and secondary synovial chondromatosis, as the latter can be categorised by loose bodies formed from dislodged osteoarthritic osteophytes [16]. As the presence of osteoarthritis alone is not enough to distinguish between primary and secondary synovial chondromatosis, investigation of loose bodies could 
aid in the differential diagnosis. In addition to their unique mineralisation patterns, PSC typically gives rise to numerous loose bodies that are homogenous in size, as seen in the subject in this study, while the secondary form of the disease most often presents with fewer loose bodies that are of varying size [9].

The location of the PSC nodules within the semimembranosus bursa is particularly noteworthy as this is the location of the more common synovial pathology known as a popliteal cyst [11]. This condition is characterised by the pathological accumulation of synovial fluid within the semimembranosus bursa, one of the six bursae around the knee that function to minimise mechanical friction forces [19, 37]. Inflammation of the intraarticular synovium, such as through osteoarthritis or PSC, leads to an effusion-caused increase in synovial fluid production within the knee joint capsule [40]. Excess fluid is able to escape into the semimembranosus bursa; however, a one-way valve prevents the fluid's return into the joint cavity $[3,15]$. Accumulation of fluid within the semimembranosus bursa manifests as pain and swelling in the back of the knee with stiffness and a limited range of motion [11], potentially mimicking PSC. Our report adds to the thin body of literature describing extraarticular cases of PSC within a popliteal cyst [12, 35] and highlights the need for additional research into the relationship between the two.

Although our findings provide novel insight into the composition of PSC nodules, extrapolation of the results should be tempered due to the limited sample size. Broadening the scope to include multiple cases of PSC would offer greater insight into the epidemiology and pathophysiology of the condition. This research was further limited by a narrow medical history of the studied subject, which was either not included in the donor documentation or withheld for the purposes of protecting anonymity. Additionally, the original in situ presentation of the pathology may have been disturbed through the dissection process, thus limiting the interpretation of radiographs. Finally, it is not known how, or if, the elemental composition of PSC nodules was altered following the systemic formalin-fixation of this donor. Prior research has demonstrated the preservation of calcium in embalmed human bone using plasma mass spectrometry [5], while animal studies have implicated formalin-fixation in the fluctuations of heavy metal concentrations [23] and mechanical properties of bone, perhaps due to instability of mineral content $[18,44]$. Future studies could use SEM-EDS to demonstrate the stability of elements of interest throughout the formalin-fixation process by comparing pre- and post-fixed tissues, thereby validating the use embalmed donors as a sample source for future SEM-EDS investigations.

\section{CONCLUSIONS}

Primary synovial chondromatosis is a rare pathology characterised by the proliferation of osseocartilaginous loose bodies from metaplastic synovium of joints, tendon sheaths, or bursae. Elemental analysis revealed PSC loose bodies to consist of a mineralised core embedded in a cartilaginous matrix, supporting a progression that mirrors endochondral ossification.

\section{Acknowledgements}

The researchers express their gratitude to the donor and their family, without whom this research would not be possible. We also thank the Kentucky Orthopaedic Clinic of Middlesboro, KY for graciously lending their staff and resources for the obtainment of the medical images, the LMU Imaging and Analysis Centre for providing the resources required to perform the SEM-EDS analyses, and the anatomy students for their contributions to the dissection.

\section{Conflict of interest: None declared}

\section{REFERENCES}

1. Apte SS, Athanasou NA. An immunohistological study of cartilage and synovium in primary synovial chondromatosis. J Pathol. 1992; 166(3): 277-281, doi: 10.1002/ path.1711660310, indexed in Pubmed: 1381426.

2. Bassir RA, Ismael F, Elbardouni $A$, et al. Bilateral synovial chondromatosis in the knee joint with both intra and extra-articular diseases. Pan Afr Med J. 2014; 19: 57, doi: 10.11604/pamj.2014.19.57.4054, indexed in Pubmed: 25667719.

3. Boijsen E. Gastrocnemius-semimembranosus bursa and its relation to the knee joint. Acta Oncol (Madr.). 1983; 22(1): 1-2.

4. Brabyn PJ, Capote A, Muñoz-Guerra MF, et al. Arthroscopic management of synovial chondromatosis of the temporomandibular joint. Case series and systematic review. J Maxillofac Oral Surg. 2018; 17(4): 401-409, doi: 10.1007/ s12663-018-1102-7, indexed in Pubmed: 30344377.

5. Bush VJ, Moyer TP, Batts KP, et al. Essential and toxic element concentrations in fresh and formalin-fixed human autopsy tissues. Clin Chem. 1995; 41(2): 284-294, indexed in Pubmed: 7874782.

6. Cadena EA. In situ SEM/EDS compositional characterization of osteocytes and blood vessels in fossil and extant turtles on untreated bone surfaces; different preserva- 
tional pathways microns away. PeerJ. 2020; 8: e9833, doi: 10.7717/peerj.9833, indexed in Pubmed: 32913685.

7. Coceska E, Gjorgievska E, Coleman NJ, et al. Enamel alteration following tooth bleaching and remineralization. J Microsc. 2016; 262(3): 232-244, doi: 10.1111/jmi.12357, indexed in Pubmed: 27197087.

8. Felbel J, Gresser U, Lohmöller G, et al. Familial synovial chondromatosis combined with dwarfism. Hum Genet. 1992; 88(3): 351-354, doi: 10.1007/BF00197274, indexed in Pubmed: 1733839.

9. Habusta S, Tuck J. Synovial chondromatosis. StatPearls. 2021.

10. Hamada J, Tamai $K$, Koguchi $Y$, et al. Case report: A rare condition of secondary synovial osteochondromatosis of the shoulder joint in a young female patient. J Shoulder Elbow Surg. 2005; 14(6): 653-656, doi: 10.1016/j. jse.2004.12.004, indexed in Pubmed: 16337537.

11. Herman AM, Marzo JM. Popliteal cysts: a current review. Orthopedics. 2014; 37(8): e678-e684, doi: 10.3928/01477447-20140728-52, indexed in Pubmed: 25102502.

12. Ho SWI, Hoa LMh, Lee KT. A rare case of concomitant intra-articular and extra-articular synovial chondromatosis of the knee joint. Ann Acad Med Singap. 2019; 48(5): 161-164, indexed in Pubmed: 31210254.

13. Hung IH, Yu K, Lavine KJ, et al. FGF9 regulates early hypertrophic chondrocyte differentiation and skeletal vascularization in the developing stylopod. Dev Biol. 2007; 307(2): 300-313, doi: 10.1016/j.ydbio.2007.04.048, indexed in Pubmed: 17544391.

14. Hunter DJ, Guermazi A. Imaging techniques in osteoarthritis. PMR. 2012; 4(5 Suppl): S68-S74, doi: 10.1016/j. pmrj.2012.02.004, indexed in Pubmed: 22632705.

15. Jayson MI, Dixon AS. Valvular mechanisms in juxta-articular cysts. Ann Rheum Dis. 1970; 29(4): 415-420, doi: 10.1136/ard.29.4.415, indexed in Pubmed: 4916772.

16. Ji JH, Shafi M, Jeong DS. Secondary synovial chondromatosis of the shoulder. Knee Surg Sports Traumatol Arthrosc. 2015; 23(9): 2624-2627, doi: 10.1007/s00167-014-30243, indexed in Pubmed: 24803015.

17. Kang $Y$, Yuan W, Ding $X$, et al. Chondrosarcoma of the para-acetabulum: correlation of imaging features with histopathological grade. Radiol Med. 2016; 121(12): 897-904, doi: 10.1007/s11547-016-0673-y, indexed in Pubmed: 27553036

18. Kikugawa $H$, Asaka T. Effect of long-term formalin preservation on the bending properties and fracture toughness of bovine compact bone. J Japan Institute Metals. 2005; 69(2): 267-271, doi: 10.2320/jinstmet.69.267.

19. LaPrade RF, Morgan PM, Wentorf FA, et al. The anatomy of the posterior aspect of the knee. An anatomic study. J Bone Joint Surg Am. 2007; 89(4): 758-764, doi: 10.2106/ JBJS.F.00120, indexed in Pubmed: 17403797.

20. Long F, Ornitz DM. Development of the endochondral skeleton. Cold Spring Harb Perspect Biol. 2013; 5(1): a008334, doi: 10.1101/cshperspect.a008334, indexed in Pubmed: 23284041.

21. Lories RJU, Derese I, Luyten FP. Modulation of bone morphogenetic protein signaling inhibits the onset and progression of ankylosing enthesitis. J Clin Invest. 2005;
115(6): 1571-1579, doi: $10.1172 / \mathrm{JCl} 23738$, indexed in Pubmed: 15902307.

22. MacKenzie $H$, Gulati $V$, Tross S. A rare case of a swollen knee due to disseminated synovial chondromatosis: a case report. J Med Case Rep. 2010; 4: 113, doi: 10.1186/17521947-4-113, indexed in Pubmed: 20416049.

23. McCormack MA, Jackson BP, Dutton J. Effects of formalin fixation on trace element concentrations in bottlenose dolphin (Tursiops truncatus) tissues. Environ Toxicol Chem. 2020; 39(6): 1149-1164, doi: 10.1002/etc.4709, indexed in Pubmed: 32164038.

24. Mikroulis D, Mavrilas D, Kapolos J, et al. Physicochemical and microscopical study of calcific deposits from natural and bioprosthetic heart valves. Comparison and implications for mineralization mechanism. J Mater Sci Mater Med. 2002; 13(9): 885-889, doi: 10.1023/a:1016556514203, indexed in Pubmed: 15348554.

25. Milgram JW. Synovial osteochondromatosis: a histopathological study of thirty cases. J Bone Joint Surg Am. 1977; 59(6): 792-801, indexed in Pubmed: 908703.

26. Milgram JW. The classification of loose bodies in human joints. Clin Orthop Relat Res. 1977(124): 282-291, indexed in Pubmed: 598088.

27. Mohr W. Is synovial osteo-chondromatosis a proliferative disease? Pathol Res Pract. 2002; 198(9): 585-588, doi: 10.1078/0344-0338-00306, indexed in Pubmed: 12440780 .

28. Murphey MD, Vidal JA, Fanburg-Smith JC, et al. Imaging of synovial chondromatosis with radiologic-pathologic correlation. Radiographics. 2007; 27(5): 1465-1488, doi: 10.1148/rg.275075116, indexed in Pubmed: 17848703.

29. Neumann J, Garrigues G, Brigman B, et al. Synovial chondromatosis. JBJS Reviews. 2016; 4(5), doi: 10.2106/jbjs. rvw.0.00054.

30. Palazzo E, Amadasi A, Boracchi M, et al. The detection of metallic residues in skin stab wounds by means of SEM-EDS: A pilot study. Sci Justice. 2018; 58(3): 232-236, doi: 10.1016/j. scijus.2017.12.007, indexed in Pubmed: 29685305.

31. Robinson D, Hasharoni A, Evron Z, et al. Synovial chondromatosis: the possible role of FGF 9 and FGF receptor 3 in its pathology. Int J Exp Pathol. 2000; 81(3): 183-189, doi: 10.1046/j.1365-2613.2000.00154.x, indexed in Pubmed: 10971739.

32. Sato J, Segami N, Suzuki T, et al. The expression of fibroblast growth factor- 2 and fibroblast growth factor receptor-1 in chondrocytes in synovial chondromatosis of the temporomandibular joint. report of two cases. Int J Oral Maxillofac Surg. 2002; 31(5): 532-536, doi: 10.1054/ ijom.2002.0248, indexed in Pubmed: 12418570.

33. Scholl DM, Taddie KL. Asymptomatic synovial chondromatosis of the ankle: an incidental finding. J Foot Ankle Surg. 2010; 49(6): 565.e13-565.e17, doi: 10.1053/j. jfas.2010.08.002, indexed in Pubmed: 20851002.

34. Sellam J, Berenbaum F. The role of synovitis in pathophysiology and clinical symptoms of osteoarthritis. Nat Rev Rheumatol. 2010; 6(11): 625-635, doi: 10.1038/ nrrheum.2010.159, indexed in Pubmed: 20924410.

35. Shah DP, Diwakar M, Dargar N. Bakers cyst with synovial chondromatosis of knee: a rare case report. J Orthop Case Reports. 2016; 6(1): 17-179. 
36. Shpitzer T, Ganel A, Engelberg S. Surgery for synovial chondromatosis. 26 cases followed up for 6 years. Acta Orthop Scand. 1990; 61(6): 567-569, doi: 10.3109/17453679008993585, indexed in Pubmed: 2281768.

37. Stein D, Cantlon M, Mackay B, et al. Cysts about the knee: evaluation and management. J Am Acad Orthop Surg. 2013; 21(8): 469-479, doi: 10.5435/JAAOS-21-08-469, indexed in Pubmed: 23908253.

38. Utashima D, Matsumura N, Suzuki T, et al. Clinical results of surgical resection and histopathological evaluation of synovial chondromatosis in the shoulder: a retrospective study and literature review. Clin Orthop Surg. 2020; 12(1): 68-75, doi: 10.4055/cios.2020.12.1.68, indexed in Pubmed: 32117541.

39. van der Valk MR, Veltman ES, Assink J, et al. Synovial chondromatosis of the hip, a case report and literature review. J Orthop. 2019; 16(3): 249-253, doi: 10.1016/j. jor.2019.02.010, indexed in Pubmed: 30923422.

40. Wang X, Blizzard L, Halliday A, et al. Association between MRI-detected knee joint regional effusion-synovitis and structural changes in older adults: a cohort study. Ann Rheum Dis. 2016; 75(3): 519-525, doi: 10.1136/annrheumdis-2014-206676, indexed in Pubmed: 25550336.

41. Wittkop B, Davies AM, Mangham DC. Primary synovial chondromatosis and synovial chondrosarcoma: a pictorial review. Eur Radiol. 2002; 12(8): 2112-2119, doi: 10.1007/ s00330-002-1318-1, indexed in Pubmed: 12136332.

42. Yu K, Ornitz DM. FGF signaling regulates mesenchymal differentiation and skeletal patterning along the limb bud proximodistal axis. Development. 2008; 135(3): 483-491, doi: 10.1242/dev.013268, indexed in Pubmed: 18094024.

43. Yu K, Xu J, Liu Z, et al. Conditional inactivation of FGF receptor 2 reveals an essential role for FGF signaling in the regulation of osteoblast function and bone growth. Development. 2003; 130(13): 3063-3074, doi: 10.1242/ dev.00491, indexed in Pubmed: 12756187.

44. Zhang G, Wang S, Xu S, et al. The effect of formalin preservation time and temperature on the material properties of bovine femoral cortical bone tissue. Ann Biomed Eng. 2019; 47(4): 937-952, doi: 10.1007/s10439-019-02197-1, indexed in Pubmed: 30671755. 